\title{
Top-Down Regulation of Default Mode Activity in Spatial Visual Attention
}

\author{
Xiaotong Wen, ${ }^{1}$ Yijun Liu, ${ }^{2,3}$ Li Yao, ${ }^{4,5}$ and Mingzhou Ding ${ }^{1}$ \\ ${ }^{1}$ J. Crayton Pruitt Family Department of Biomedical Engineering and ${ }^{2}$ Department of Psychiatry and McKnight Brain Institute, University of Florida, \\ Gainesville, Florida, 32611, ${ }^{3}$ Department of Biomedical Engineering, Peking University, Beijing, China, 100871, ${ }^{4}$ College of Information Science and \\ Technology and ${ }^{5}$ National Key Laboratory of Cognitive Neuroscience and Learning, Beijing Normal University, Beijing, China, 100875
}

\begin{abstract}
Dorsal anterior cingulate and bilateral anterior insula form a task control network (TCN) whose primary function includes initiating and maintaining task-level cognitive set and exerting top-down regulation of sensorimotor processing. The default mode network (DMN), comprising an anatomically distinct set of cortical areas, mediates introspection and self-referential processes. Resting-state data show that TCN and DMN interact. The functional ramifications of their interaction remain elusive. Recording fMRI data from human subjects performing a visual spatial attention task and correlating Granger causal influences with behavioral performance and blood oxygen level-dependent (BOLD) activity we report three main findings. First, causal influences from TCN to DMN, i.e., TCN $\rightarrow$ DMN, are positively correlated with behavioral performance. Second, causal influences from DMN to TCN, i.e., DMN $\rightarrow$ TCN, are negatively correlated with behavioral performance. Third, stronger DMN $\rightarrow$ TCN are associated with less elevated BOLD activity in TCN, whereas the relationship between TCN $\rightarrow$ DMN and DMN BOLD activity is unsystematic. These results suggest that, during visual spatial attention, top-down signals from TCN to DMN regulate the activity in DMN to enhance behavioral performance, whereas signals from DMN to TCN, acting possibly as internal noise, interfere with task control, leading to degraded behavioral performance.
\end{abstract}

\section{Introduction}

The task control network (TCN) and the default mode network (DMN) are two fundamental cortical systems. Consistently activated in a wide variety of cognitive paradigms, TCN, containing dorsal anterior cingulate cortex (dACC) and bilateral anterior insula (AI) (Dosenbach et al., 2006), initiates and maintains tasklevel control, selects appropriate sensorimotor mapping, and suppresses irrelevant distracting information (Logan and Gordon, 2001; Botvinick et al., 2004; Kerns et al., 2004; Dosenbach et al., 2006; Corbetta et al., 2008; Sridharan et al., 2008; Nelson et al., 2010; Fan et al., 2011). In contrast, consistently deactivated in cognitive paradigms demanding externally oriented attention, $\mathrm{DMN}$, containing posterior cingulate cortex (PCC), ventral (vMPFC) and dorsal (dMPFC) medial prefrontal cortices, bilateral inferior parietal lobe, and lateral temporal cortex (Buckner et al., 2008), mediates internal mentation and self-referencing and underlies emotional regulation (Maddock, 1999; Simpson et al., 2001) and mind wandering (Mason et al., 2007). Resting-state blood oxygen level-dependent (BOLD) signals from these two networks are anti-correlated (Greicius and Menon, 2004; Fox et

Received Oct. 22, 2012; revised Feb. 27, 2013; accepted March 6, 2013.

Author contributions:X.W., Y.L., L.Y., and M.D. designed research; X.W., Y.L., L.Y., and M.D. performed research; X.W. and M.D. contributed unpublished reagents/analytic tools; X.W. and M.D. analyzed data; X.W., Y.L., L.Y., and M.D. wrote the paper.

This research was supported by National Institutes of Health Grant MH097320, National Natural Science Foundation of China (NSFC) Grants 81271549 and 61131003, and State Key Program of NSFC Grant 60931003.

The authors declare no competing financial interests.

Correspondence should be addressed to Mingzhou Ding, J. Crayton Pruitt Family Department of Biomedical Engineering, University of Florida, BMS J285, P.0. Box 116131, Gainesville, FL 32611. E-mail: mding@bme.ufl.edu. DOI:10.1523/JNEUROSCI.4939-12.2013

Copyright $\odot 2013$ the authors $\quad 0270-6474 / 13 / 336444-10 \$ 15.00 / 0$ al., 2005; Dosenbach et al., 2008; Ding et al., 2009; Fitzgerald et al., 2010; Smallwood et al., 2012), suggesting interaction, but the functional significance of this interaction remains to be understood.

According to a recent theory, TCN maintains task control over other brain areas by issuing top-down signals to regulate their activities (Dosenbach et al., 2006). In the current formulation of the theory, areas receiving these regulatory signals are mainly task-positive areas, namely areas activated during external tasks (Fox et al., 2005); task-negative areas (deactivated), despite the clear functional necessity that their activities be regulated according to task conditions (Sambataro et al., 2010; van Eimeren et al., 2009; Ossandón et al., 2011; Sharp et al., 2011), are not considered. Recent data suggest that the activities of tasknegative areas may be regulated by TCN as well (Ossandón et al., 2011; Gao and Lin, 2012). Clinically, disrupted functional connectivity between DMN and executive control structures, including TCN regions (Church et al., 2009; Sato et al., 2012; Spreng and Schacter, 2012) or damaged structural connectivity between TCN nodes (Bonnelle et al., 2012), are thought to partly underlie the dysregulation of DMN activity in brain disorders. These evidences appear to support the extension of the domain of influence of TCN to include DMN. Our first goal is to test this hypothesis.

DMN activity fluctuates slowly. During the elevated phase of DMN activity, particularly in its midline regions (mDMN), task performance deteriorates (Spreng and Schacter, 2012). This may be understood by viewing $\mathrm{mDMN}$ as a source of internal interference or noise (Greicius and Menon, 2004; Buckner et al., 2008; Smallwood et al., 2012). Supporting this view, PCC and MPFC 
A

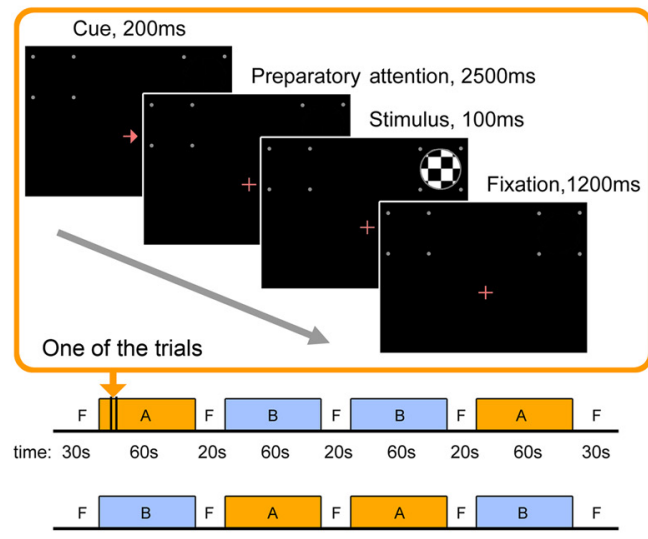

$A$ : attention block $B$ : passive view block $F$ : fixation interval 3 ABBA runs and $3 \mathrm{BAAB}$ runs for each subject

D

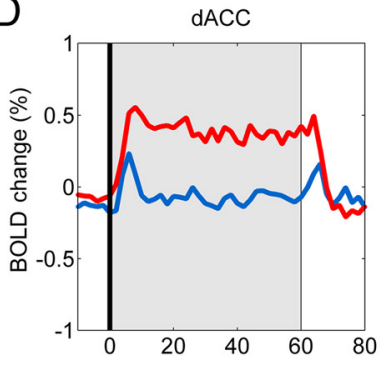

PCC

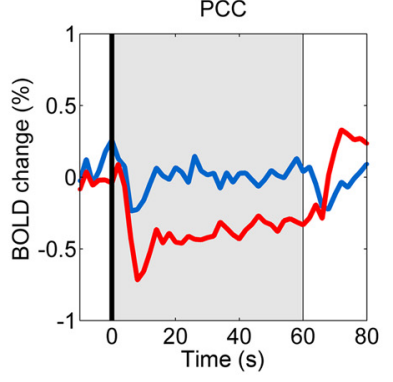

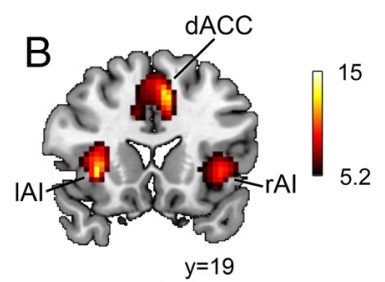

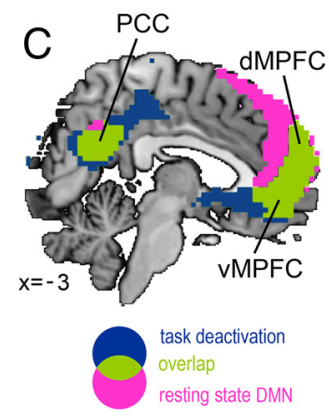

IAI

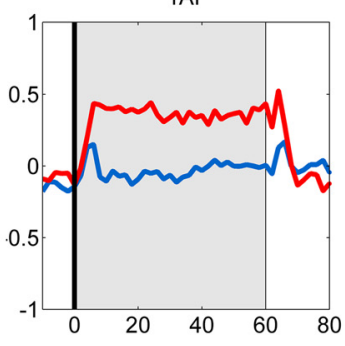

dMPFC

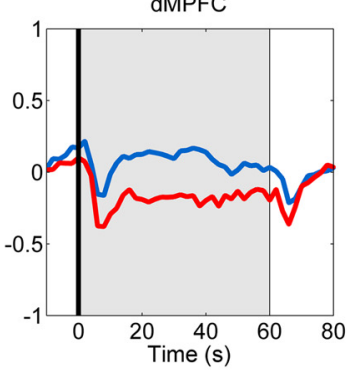

Attention Passive view

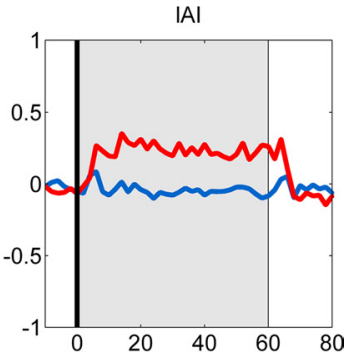

VMPFC

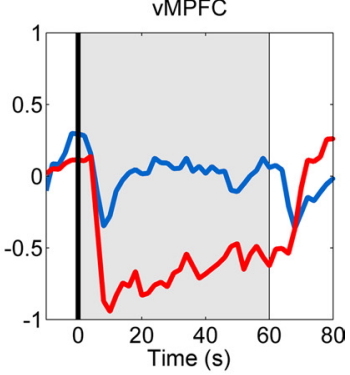

Figure 1. Experimental paradigm and definition of ROls. $A$, In each of 12 attention blocks (A blocks), the subject performed a trial-by-trial cued spatial attention task. At the beginning of each trial, the fixation cross was transiently replaced by a left-pointing or right-pointing arrow, which directed the subject to initiate and maintain covert attention to the cued hemifield. After a delay, standard or target stimuli appeared in either the attended hemifield or unattended hemifield. The subject made a speedy key response to the small probability target stimuli in the attended hemifield when they appeared and withheld response to all other stimuli. In 12 passive view blocks (B blocks) stimuli were presented in the same way as in attention blocks but the subject was only required to fixate. F denotes a period of fixation. $\boldsymbol{B}$, Group activation $(n=12)$ by contrasting attention blocks against passive view blocks ( $T>5.20, p<0.002$, FDR corrected). Regions of dACC and bilateral Al are selected as ROls of TCN. C, Group deactivation ( $n=12, T<-4.75, p<0.005$, FDR corrected) is indicated in blue, and group resting-state ICA map ( $n=12, T>4.75, p<$ 0.005 , FDR corrected) of DMN is indicated in purple. Midline regions of PCC, AMPFC, and vMPFC are selected as ROIs of DMN. $\boldsymbol{D}$, Percentage BOLD signal change averaged within each ROI and then across blocks and subjects. Red color denotes the attention condition and blue color the passive view condition. The gray area outlines the block period.

have been identified as chiefly responsible for attentional lapses and mind wandering (Mason et al., 2007; Christoff et al., 2009; Anticevic et al., 2010). In brain disorders, mDMN regions are less deactivated relative to controls in cognitive tasks, contributing to cognitive deficits (van Eimeren et al., 2009; Santhanam et al., 2011; Bonnelle et al., 2012). Less suppressed DMN may disrupt task performance by issuing signals to interfere with the control set maintained by TCN. The testing of this hypothesis is our second goal.
These goals were accomplished by collecting fMRI data from human subjects performing a visual spatial attention experiment. General linear modeling (GLM) and independent component analysis (ICA) were applied to identify regions of interest (ROIs) in TCN and DMN. Their directional influences were then assessed by Granger causality and correlated with accuracy, reaction time (RT), and BOLD activity level.

\section{Materials and Methods}

Experiment. Thirteen healthy right-handed individuals with normal or corrected-to-normal vision participated in the study. The experimental protocol, which included both restingstate and task fMRI, was approved by the Institutional Review Board of the Beijing Normal University. One male subject failed to perform the attention task according to instructions and was not included in further analysis.

Resting state was recorded first, in which subjects were instructed to relax with their eyes closed for $10 \mathrm{~min}$. The visual spatial attention experiment followed, which consisted of 12 attention blocks and 12 passive view blocks. The experimental timeline is schematically illustrated in Figure 1A. In attention blocks (labeled A blocks), each trial started with a cue, instructing the subject to initiate and maintain covert attention to the left or right hemifield. After a 2500 ms delay, a standard or a target stimulus of $100 \mathrm{~ms}$ in duration appeared either inside the attended hemifield (valid trial) or inside the unattended hemifield (invalid trial). The subject was required to make a speedy keypress response only to the target stimulus when it appeared in the cued hemifield. The standard stimulus appeared $80 \%$ of the time with $50 \%$ validity and the target stimulus appeared $20 \%$ of the time with $50 \%$ validity. In passive view blocks (labeled B blocks), the schedule of stimulus presentation remained the same, but neither attention nor response was required; the subject simply maintained fixation. The two types of blocks were arranged in an $\mathrm{ABBA}$ or $\mathrm{BAAB}$ order in each run (session). For each participant, three $\mathrm{ABBA}$ runs and three $\mathrm{BAAB}$ runs were arranged in an interleaved manner. Each block lasted $60 \mathrm{~s}$ (15 trials), with $20 \mathrm{~s}$ fixation intervals inserted between successive blocks. More details of the paradigm can be found in the study of Wen et al. (2012a).

Data acquisition and preprocessing. MRI scanning was performed on a 3 tesla Siemens Magnetom Trio whole-body MRI system at the Beijing Normal University MRI Center. The functional scans were acquired with a $2^{*}$-weighed echo-planar imaging sequence [echo time (TE), $30 \mathrm{~ms}$; repetition time (TR), $2000 \mathrm{~ms}$; flip angle, $90^{\circ}$ ], with 33 axial slices in each volume (field of view, $200 \times 200$ $\mathrm{mm}^{2}$; matrix size, $64 \times 64$; slice thickness, $3.60 \mathrm{~mm}$, giving a voxel size of $3.13 \times 3.13 \times 3.60 \mathrm{~mm}^{3}$ ). There were 300 whole-brain volumes for the resting state session and 180 whole-brain volumes for each of the six task runs. High-resolution anatomic images were acquired with a T1weighted 128 slice MPRAGE sequence (TR, $2530 \mathrm{~ms}$; TE, $3.39 \mathrm{~ms}$; flip angle, $7^{\circ}$; inversion time, $1100 \mathrm{~ms}$; voxel size, $1 \times 1.33 \times 1 \mathrm{~mm}^{3}$ ). 
fMRI data were preprocessed using SPM2 (http://www.fil.ion.ucl.ac.uk/spm/). The steps included slice timing, motion correction, coregistration to the individual's anatomical image, normalization to the Montreal Neurological Institute (MNI) template (Friston et al., 1995), and resampling into a $3 \times 3 \times 3 \mathrm{~mm}^{3}$ per voxel resolution. For GLM analysis and ICA, spatial smoothing of normalized images was done with an $8 \mathrm{~mm}$ full-width at halfmaximum Gaussian core. (Note that spatial smoothing was not done for Granger causality analysis as explained below.) Global scaling was applied to remove the global signal before GLM analysis. Although how to remove the global signal is likely to be problem specific (Zarahn et al. 1997; Aguirre et al., 1998; Gavrilescu et al., 2002; Macey et al., 2004; Junghöfer et al., 2005), we found that, for our data, global scaling made the BOLD time series from activated regions more correlated with the task design and provided more precise activation results, in line with many previous studies (Birn et al. 2006; Lund et al., 2006; Fox et al., 2009). Additionally, the removal of global signal made the residual BOLD time series more stationary (Rogers et al., 2007; Sridharan et al., 2007), which is required by Granger causality analysis.

Task activation and ROIs. For the attention task, two kinds of regressors, one corresponding to the attention condition and one the passive view condition, were used to fit the GLM. Each regressor was generated by convolving the blocked rectangular function corresponding to a given experimental condition with a canonical hemodynamic response function. In the random-effects analysis, for each subject, from the fitted GLM, the attend condition and the passive view condition were compared to produce the contrast image. These contrast images were fed into a GLM that implemented a one-sample $t$ test to yield group-level activations. False discovery rate (FDR) control was applied to correct for multiple comparisons (Bennett et al., 2009; Poldrack and Mumford, 2009). ROIs for TCN were generated by intersecting the group activated regions $(T>5.20, p<$ 0.002 , FDR corrected) with spheres of $5 \mathrm{~mm}$ in radius centered at the voxels with maxima local $T$ values ( $T>8.24, p<0.0002$, FDR corrected).

ROIs for DMN were identified by applying group ICA to resting-state data. Twenty-five aggregate independent components (ICs) were identified using the GIFT toolbox (http://icatb.sourceforge.net/) in which the number of components was determined by the minimum description length criterion. All aggregate ICs were visually inspected, and the IC representing DMN was selected (Buckner et al., 2008). mDMN ROIs were generated by intersecting the group IC map $(T>4.75, p<0.005$, FDR corrected) with spheres of $5 \mathrm{~mm}$ in radius centered at the voxels with maxima local $T$ values ( $T>8.24, p<0.0002$, FDR corrected) in the midline regions of the map.

Granger causality analyses. Testing of our hypotheses requires that neuronal interactions be decomposed into their directional components. We chose Granger causality for this purpose because of its simplicity, its demonstrated effectiveness, and our extensive experience with the method (Ding et al., 2006; Bollimunta et al., 2008, 2011; Wen et al., 2012a). Its basic idea is that, if the history of one time series can be used to facilitate the prediction of the future of another time series, then we say there is a Granger causal influence from the former to the latter (Granger, 1967). Recent work applying this method to fMRI data has offered useful insights into the functional organization of both healthy and diseased brain networks (Abler et al., 2006; Rypma et al., 2006; Sridharan et al., 2007; Bressler et al., 2008; Liao et al., 2010; Hamilton et al., 2011; Jiao et al., 2011; Miao et al., 2011; Ge et al., 2012; Wen et al., 2012a).
B
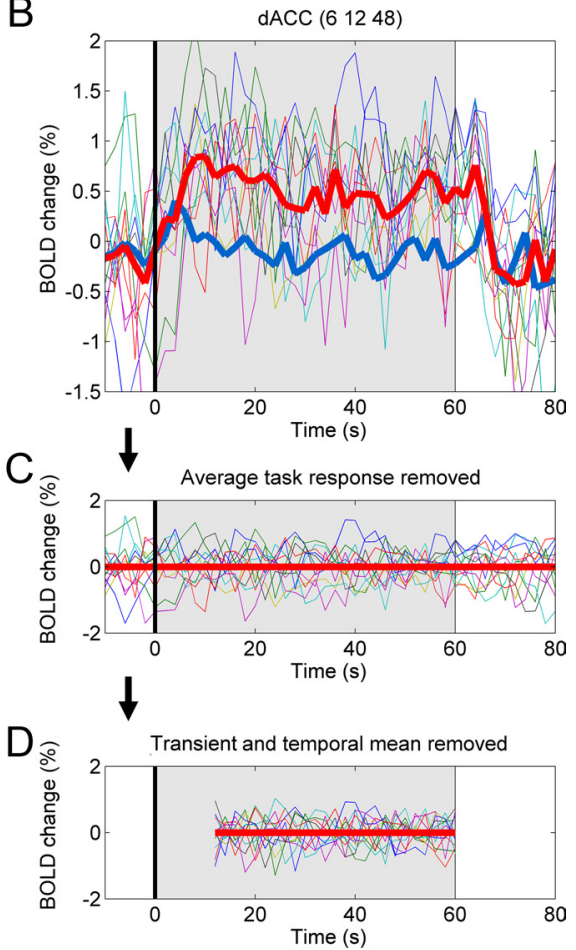

Figure 2. Data preprocessing and flowchart for Granger causality analysis. A, Schematic diagram of the preprocessing protocol. 列 average task response was removed in each block. $\boldsymbol{D}$, Residual BOLD time series had their first five time points discarded and temporal mean removed before being submitted to Granger causality analysis.

The analysis protocol has five steps (Wen et al., 2012a) (Fig. 2A). First, for each voxel in a given ROI, the fMRI time series before spatial smoothing was extracted from the normalized functional images, and the global signal were removed (Smith et al., 1999) using the SPM2 global scaling function (http://www.fil.ion.ucl.ac.uk/spm/). The reason for extracting individual voxel time series before spatial smoothing is because spatial smoothing or averaging within ROI may run the risk of losing valuable temporal information critical for Granger causality analysis. Second, the mean signal value during the baseline fixation period (Fig. $1 \mathrm{~A}, \mathrm{~F}$ period) was calculated, and the percentage BOLD signal change was obtained by subtracting the mean signal value from the fMRI time series and then dividing the difference by the mean signal value. This step, although not required for Granger causality analysis, helps with the normalization and comparison of data (Fig. 2B). Third, for each voxel, the data of the 12 attention blocks were averaged to obtain the average task response (Fig. $2 B$ ). This average task response was subtracted from each attention block to yield the block-level residual BOLD fluctuation time series (Fig. 2C). Fourth, for the block-level BOLD residual time series, the first five time points (10 s) were discarded (Garrett et al., 2011) to eliminate the transient effects, and the temporal mean was removed to meet the zero-mean requirement assumed by the autoregressive (AR) model (Ding et al., $2000,2006)$. The temporal-mean-removed residual time series, containing 25 time points, were treated as realizations of an underlying stochastic process. Fifth, for a given pair of ROIs, Granger causality was calculated on the zero-mean residual time series following Geweke's formulation (Geweke, 1982; Ding et al., 2006) for all pairwise combinations of voxels between the two ROIs and averaged (Wen et al., 2012a). Based on Bayesian information criterion, the order of AR model was determined to be 1 (Roebroeck et al., 2005; Bressler et al., 2008; Hamilton et al., 2011; Wen et al., 2012a).

Granger causality requires that the time series be approximately stationary (Ding et al., 2006). We tested the stationarity of block-level residual BOLD time series using the Kwiatkowski-Phillips-Schmidt-Shin test (Kwiatkowski et al., 1992) and found that 99\% of the time series passed the test. To examine how well the AR models captured the tem- 
poral structure in the BOLD data, we applied the Durbin-Watson test (Durbin and Watson, 1950) to the innovation series from each of the estimated AR models (Seth, 2005). Ninety-nine percent of the pairwise models passed the test.

Linking causal influences with behavior. Behavioral performance in each attention block was assessed by accuracy and RT (Wen et al., 2012a). Accuracy was defined as the ratio between the number of correctly performed trials and the total number of trials. Correctly performed trials were the trials in which the subject either responded to the target in the cued hemifield or withheld response to all other stimuli. RT for each attention block is the mean RT to attended targets. For a missed target in the valid hemifield, the RT for that trial was set at two times the participant's average RT during the entire experiment (Wen et al., 2012a). Both accuracy and RT were converted into $z$-sores. To be compatible with the convention used for accuracy, we multiplied the RT $z$-score by -1 so that, for both accuracy and RT, higher $z$-scores mean better performance. For each subject, 12 attention blocks were ranked according to accuracy and sorted into 10 groups in ascending order, with each group consisting of three neighboring blocks. For RT, because the valid target was infrequent and trials were randomized, there were rare attention blocks in which no valid target requiring a key response appeared. For each of the 10 subjects who had 11 blockwise RTs, the 11 blocks were ranked and sorted into nine groups in ascending order, with each consisting of three neighboring blocks. For the remaining two subjects who had 10 available blockwise RTs, there were also nine sorted groups, with the last group consisting of two neighboring blocks.

Granger causality and behavioral performance in each block were averaged across blocks within each group and then across subjects. The average Granger causality for each group was plotted as a function of the average behavioral performance for the same group. The relationship in the scatter plot was assessed by both Spearman's rank correlation and Pearson's correlation. A correlation is considered significant if $p<0.05$ for both methods. Results are reported in terms of Spearman's rank correlation. If the correlation between one causal influence and accuracy, RT, or both was significantly positive at $p<0.05$, then this influence is associated with better behavioral performance. In contrast, if the correlation was significantly negative at $p<0.05$, the influence is associated with worse behavioral performance. If a correlation was significantly positive for one behavioral measure but significantly negative for the other, the role of this connection is considered ambiguous. Ambiguous causal influences in this study were found to be very rare.

Linking causal influences with BOLD activity levels. For a given pair of ROIs, to examine how activity levels in each of the two areas are related to causal influences between them, the level of BOLD activity of each block was estimated, $z$-scored, sorted, grouped, and correlated with Granger causality using the same procedure given above. The same was done at the network level for TCN and DMN.

Linking behavioral performance with BOLD activity levels. To examine how BOLD activity levels in a given ROI are related to behavioral performance, RT and accuracy of each block was $z$-scored, sorted, grouped, and correlated with averaged BOLD activity level using the same procedure given above.

\section{Results}

Twelve subjects performed the attention task according to instructions. The overall mean RT was $426.80 \pm 47.45 \mathrm{~ms}$, and the mean accuracy was $82.13 \pm 8.76 \%$.

\section{ROI selection}

Attention blocks were contrasted against passive view blocks in Figure $1 B$ to yield suprathreshold $T$ values $(T>5.20, p<0.002$, FDR corrected), which were color coded and projected on a spatially normalized high-resolution MNI T1 template (Collins et al., 1994). As expected, dACC and bilateral AI of the TCN were activated. For the same set of brain structures, other terms, such as the core task-set system (Dosenbach et al., 2006) and the salience network (Menon and Uddin, 2010; Menon, 2011), have
Table 1. Center coordinates of the six ROls

\begin{tabular}{lllrrr}
\hline & & & \multicolumn{4}{c}{ MNI coordinates $(\mathrm{mm})$} \\
\cline { 5 - 6 } ROI & $T$ value & $p($ FDR $)$ & $x$ & \multicolumn{1}{c}{$y$} & \multicolumn{1}{c}{$z$} \\
\hline dACC & 14.64 & $<0.0002$ & 6 & 12 & 48 \\
rAI & 16.57 & $<0.0002$ & 36 & 27 & 6 \\
IAI & 14.11 & $<0.0002$ & -30 & 21 & 0 \\
PCC & $10.51($ ICA $)$ & $<0.0002$ & 3 & -54 & 27 \\
dMPFC & 27.35 (ICA) & $<0.0002$ & -9 & 60 & 21 \\
vMPFC & 9.78 (ICA) & $<0.0002$ & -3 & 54 & -9 \\
\hline
\end{tabular}

also been used to refer to them. The three TCN ROIs were generated by intersecting each of the three activated TCN regions ( $T>5.20, p<0.002$, FDR corrected) with a sphere of $5 \mathrm{~mm}$ in radius centered at the voxel with the maxima local $T$ value $(T>$ $8.24, p<0.0002$, FDR corrected). The coordinates of the three maximally activated voxels are given in Table 1 . The number of voxels in the ROIs ranged from 17 [right AI (rAI)] to 19 [dACC and left $\mathrm{AI}(\mathrm{lAI})]$. Other activated regions included frontal eye fields and intraparietal sulcus of the dorsal attention network and right temporal parietal junction and right middle frontal gyrus of the ventral attention network. The interaction between these attention networks and its functional significance have been the subjects of a recent study (Wen et al., 2012a) and will not be pursued here.

Regions deactivated by the task were more diffuse. To more precisely identify the midline regions of DMN, we applied group ICA to the resting-state data recorded in the same scanning session. The spatial IC map ( $T>4.75, p<0.005$, FDR corrected) containing the three midline regions of DMN (PCC, vMPFC, and dMPFC) is shown in Figure $1 C$. The center voxel coordinates for the three $\mathrm{mDMN}$ ROIs are given in Table 1. All the center voxels were contained in the task-deactivated regions (Fig. $1 C$, green regions, in which $T<-4.75, p<0.005$, FDR corrected). The number of voxels in these mDMN ROIs ranged from 15 (vMPFC) to 19 (PCC and dMPFC).

\section{Time course of BOLD response}

The task response in a given ROI was calculated by averaging the percentage BOLD signal change first within the ROI and then across blocks and subjects (Fig. 1D). Sustained BOLD elevation with attention is clearly seen in TCN ROIs, whereas sustained BOLD activity suppression of varying degrees with attention is clearly seen in DMN ROIs. The gray zone delineates the time period between the beginning and the end of a block.

\section{Causal interactions between AACC and PCC}

To illustrate the essential elements of our approach, we start by considering two ROIs: dACC and PCC. For each subject, the accuracy and the mean RT of each attention block were converted into $z$-scores, and all attention blocks were sorted in an ascending manner into accuracy and RT groups (see Materials and Methods). Granger causal influences dACC $\rightarrow$ PCC and PCC $\rightarrow$ dACC were calculated for each group and plotted as a function of the mean performance $z$-score of that group. As shown in Figure 3, $A$ and $B$, dACC $\rightarrow$ PCC is positively correlated with both performance measures $(r=0.87, p<0.005$ for accuracy and $r=0.77$, $p<0.05$ for RT), meaning that the stronger the causal influence from dACC to PCC the better the behavioral performance (behavior enhancing). (Note that, for RT, a negative sign was applied when converting it to $z$-score so that the larger the $z$-score, the shorter the RT and the better the performance.) In contrast, Granger causal influence in the opposite direction, $\mathrm{PCC} \rightarrow \mathrm{dACC}$ 
A
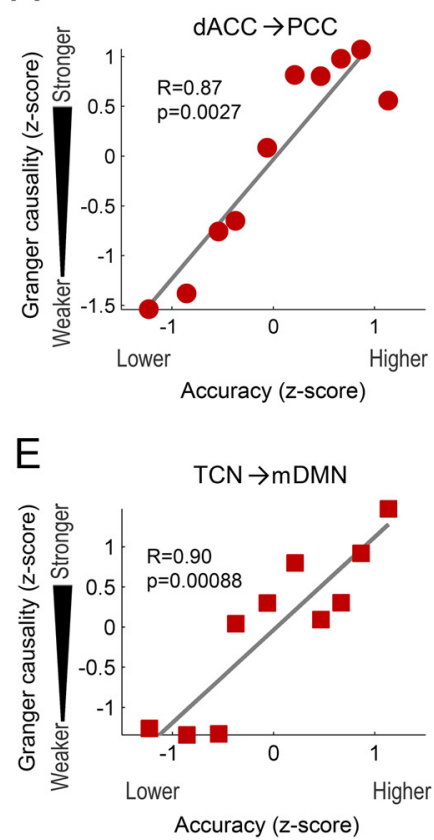

B

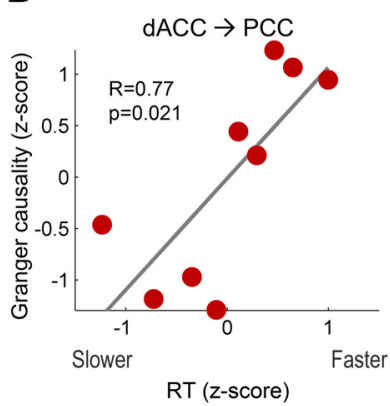

F

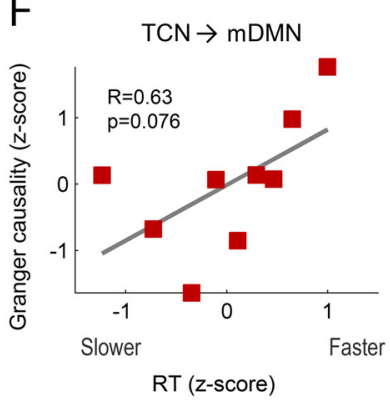

C

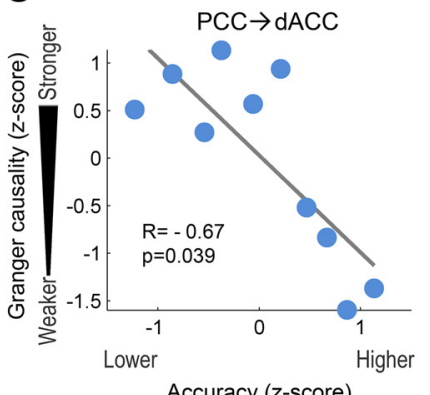

G

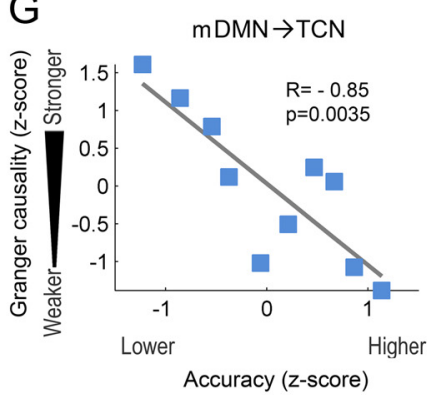

D

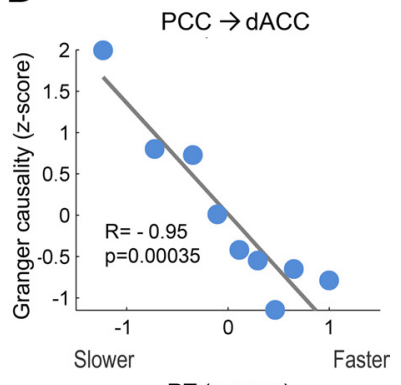

RT (z-score)

$\mathrm{H}$

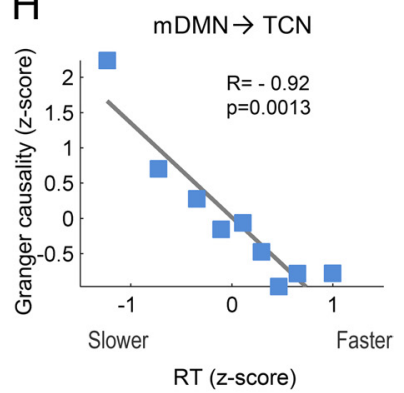

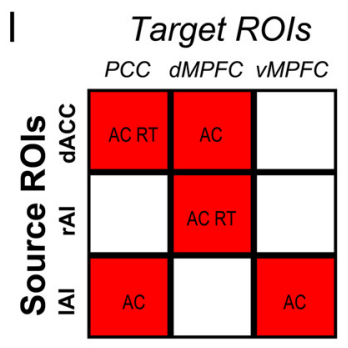

J Source ROIs
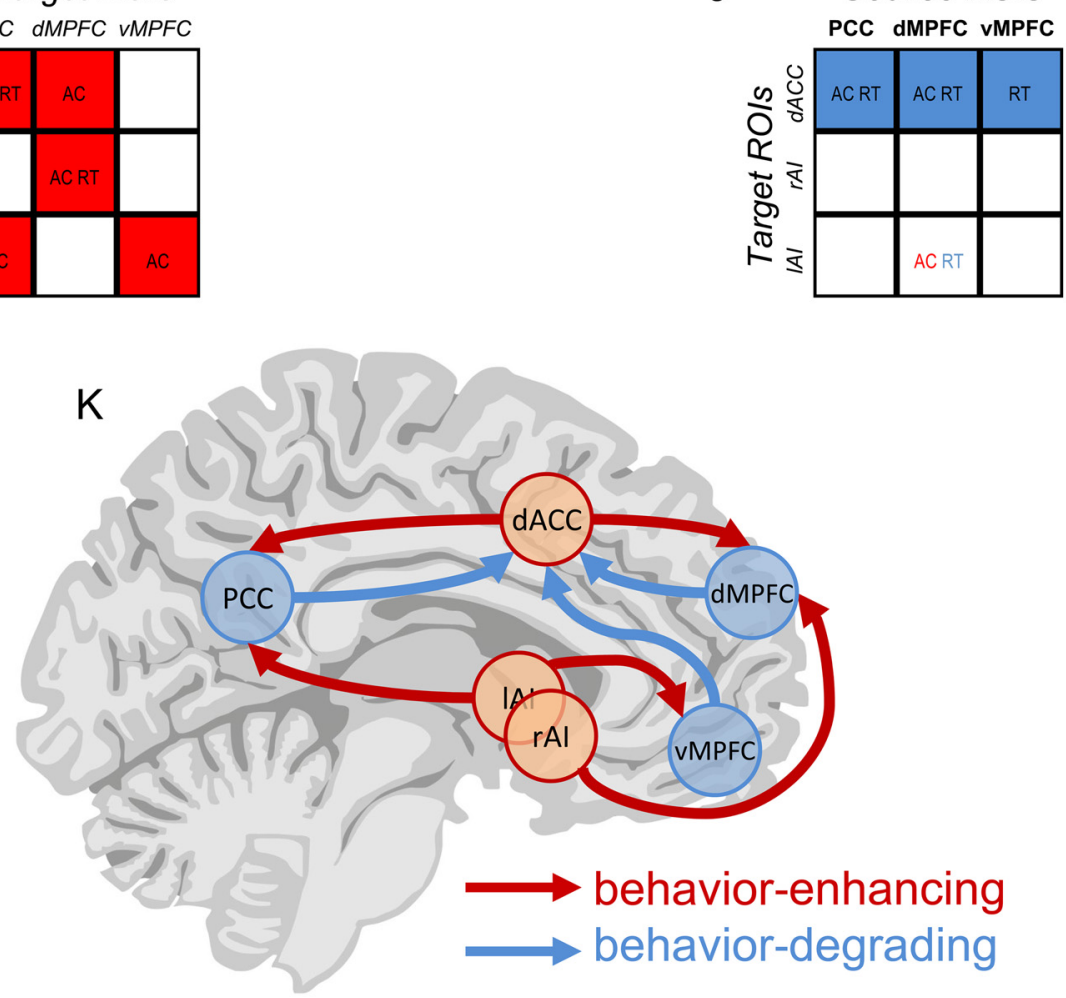

Figure 3. Relation between Granger causal influences and behavioral performance. $A-D$, Granger causal influences as functions of accuracy score (AC) or RT score (RT) for the ROI pair PCC and dACC. The RT scores have been premultiplied by -1 so that larger RT scores denote shorter RT and hence better performance. Red color indicates positive correlation (behavior enhancing) and blue color indicates negative correlation (behavior degrading). Linear fits are shown, with $R$ being the Spearman's correlation coefficient and $p$ the significance level. $\boldsymbol{E}$ - $\boldsymbol{H}$, Network-to-network causal influences as functions of AC or RT. Conventions are otherwisethesameas in $\boldsymbol{A}-\boldsymbol{D} . \mathbf{I}, \boldsymbol{J}$, Matrix view of the relationship between Granger causality and behavioral performance for all ROI pairs. A cell is colored red (blue) when Granger causal influence it represents is positively (negatively) correlated with $A C, R T$, or both at $p<0.05$ (see Materials and Methods). Otherwise, it is left transparent. If the causal influence is positively correlated with one performance measurement but negatively correlated with the other at $p<0.05$, the cell is so indicated. $\boldsymbol{K}$, A diagrammatic summary of the results in $\boldsymbol{I}$ and $\boldsymbol{J}$.

(Fig. 3C,D), is negatively correlated with performance $(r=-0.67$, $p<0.05$ for accuracy and $r=-0.95, p<0.0005$ for RT), suggesting that the stronger the causal influence from PCC to dACC the worse the behavioral performance (behavior degrading).
Causal interactions at the network level

Granger causal influences for all internetwork ROI pairs were calculated and averaged according to two categories, TCN $\rightarrow$ $\mathrm{mDMN}$ and $\mathrm{mDMN} \rightarrow \mathrm{TCN}$. As shown in Figure $3 E-H$, stronger 
$\mathrm{TCN} \rightarrow \mathrm{mDMN}$ is associated with better behavioral performance $(r=0.93, p<0.0005$ for accuracy and $r=0.63 p=0.076$ for RT $)$, whereas stronger causal influence in the opposite direction, $\mathrm{mDMN} \rightarrow \mathrm{TCN}$, is associated with worse behavioral performance $(r=-0.85, p<0.005$ for accuracy and $r=-0.92, p<$ 0.005 for RT). These results extend the findings at the level of two ROIs (dACC and PCC) to the level of two networks (TCN and $\mathrm{mDMN})$.

\section{Contributions of individual ROIs}

Results for all internetwork ROI pairs are shown in Figure 3, $I$ and J. TCN ROIs are listed along the vertical axis and DMN ROIs the horizontal axis. Source ROIs are ROIs from which causal influences originate. Target ROIs are ROIs toward which the causal influences flow. A cell in the matrix is colored red if the corresponding directional influence is positively correlated $(p<0.05)$ with RT, accuracy, or both; in other words, red cells indicate behavior-enhancing influences. Similarly, a cell is colored blue if its corresponding directional influence is negatively correlated $(p<0.05)$ with RT, accuracy, or both; namely, blue cells indicate behavior-degrading influences. Otherwise, the cell is left transparent. Cells in which accuracy and RT exhibited opposite correlations with causal influences are marked with colored letters.

From TCN to mDMN (Fig. 3I), all five cells with significant Granger-behavior correlations are red, indicating behaviorenhancing influences. From mDMN to TCN, besides one cell whose function is ambiguous, the remaining cells with significant Granger-behavior correlations are blue, indicating behaviordegrading influences. The results in Figure 3, $I$ and $J$, are further schematically illustrated in Figure $3 K$, in which red and blue arrows denote behavior-enhancing and behavior-degrading influences, respectively.

\section{Causal influences and regional BOLD activity}

How do causal influences impact BOLD activity in the target area? To investigate this question, we correlated Granger causality with target area BOLD activity level. For dACC and PCC, the magnitude of PCC $\rightarrow$ dACC is negatively correlated with the BOLD level in dACC $(r=-0.72, p<0.05)$, indicating that the stronger the causal influence from PCC to dACC, the less elevated the BOLD level in dACC (Fig. 4A). In the opposite direction, dACC $\rightarrow$ PCC and the BOLD level of PCC also show a negative trend $(r=-0.60, p=0.07)$, meaning that stronger $\mathrm{dACC} \rightarrow$ PCC is associated with more depressed BOLD activity in PCC (Fig. 4B). The same analysis was applied to all internetwork ROI pairs between TCN and mDMN. The result is displayed in a matrix form in Figure 4, $C$ and $D$. In general, causal influences from mDMN ROIs (Fig. 4D) are associated with less elevated BOLD activities in TCN ROIs $(p<0.05$ or $p<0.1)$, whereas causal influences from TCN ROIs have a more complex relationship with $\mathrm{mDMN}$ BOLD activities $(p<0.05$ or $p<0.1)$ (Fig. 4C)

How do BOLD activities in the source area impact causal influences emanating from the area? To investigate this question, we correlated Granger causality with the BOLD activity level in the source region and found that such correlations were rare at the ROI level. The only ROI exhibiting such correlation is rAI, in which its BOLD level is significantly negatively correlated with the magnitude of $\mathrm{rAI} \rightarrow \mathrm{vMPFC}(r=-0.96, p<0.0001)$. However, at the network level, we found that mean BOLD level in $\mathrm{mDMN}$ is significantly positively correlated with $\mathrm{mDMN} \rightarrow$ TCN $(r=0.68, p<0.05)$, indicating that less depressed activity in $\mathrm{mDMN}$ is associated with stronger $\mathrm{mDMN} \rightarrow \mathrm{TCN}$, which is
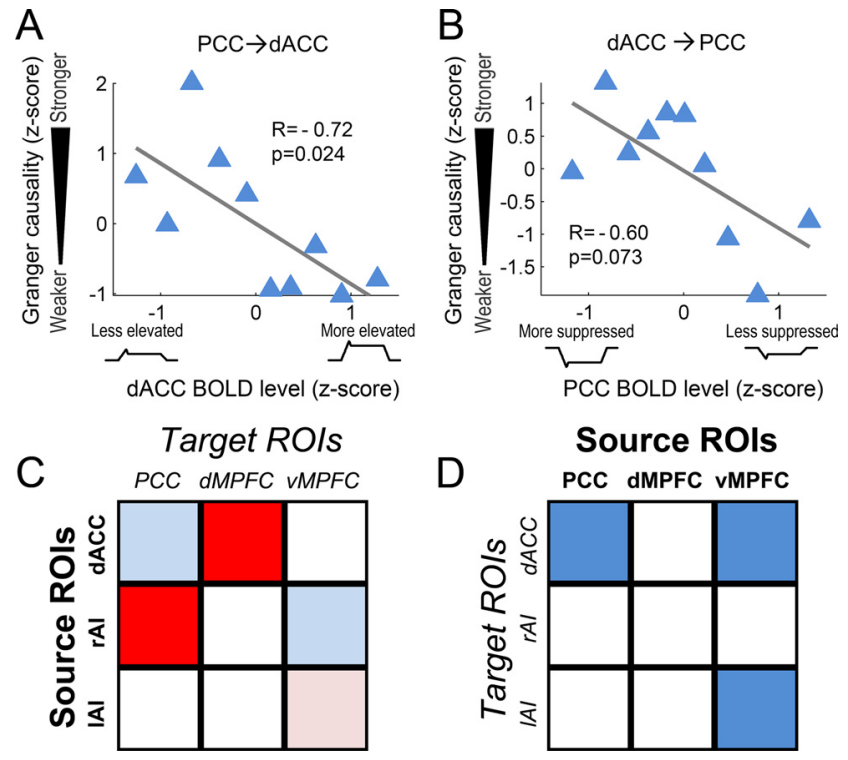

Figure 4. Relationship between Granger causal influences and regional BOLD activities. $A, B$ Granger causal influences as functions of BOLD activity levels in target ROls. C, D, Matrix view of the correlation between causal influences and BOLD activity levels. A cell is colored blue (red) if the corresponding influence is negatively (positively) correlated with the BOLD level in the target ROl. A deeper color denotes a significance level of $p<0.05$, and a shallower color denotes a significance level of $p<0.1$.

further associated with worse performance (Fig. $3 G, H$ ). No correlation was found between TCN $\rightarrow \mathrm{mDMN}$ and TCN BOLD level.

\section{Regional BOLD activity and behavior}

We correlated BOLD level in each ROI with accuracy and RT and found that the mean BOLD level in PCC is negatively correlated with accuracy $(r=-0.68, p<0.05)$. A negative trend was seen between PCC BOLD level and RT $(r=-0.65, p=0.067)$. This finding is consistent with previous reports that elevated PCC BOLD is associated with deteriorated task performance (van Eimeren et al., 2009; Santhanam et al., 2011; Bonnelle et al., 2012). The BOLD level in IAI and vMPFC is negatively and positively correlated with accuracy, respectively. At the network level, the BOLD level of TCN and mDMN showed no consistent correlation with behavioral performance.

\section{Discussion}

Recording fMRI from subjects performing a spatial visual attention task and combining Granger causality analysis with the naturally occurring variability in behavioral performance, the following results were found: (1) TCN $\rightarrow$ mDMN influences are positively correlated with behavioral performance (behavior enhancing); (2) mDMN $\rightarrow$ TCN influences are negatively correlated with behavioral performance (behavior degrading); (3) less depressed mDMN BOLD activity is associated with stronger $\mathrm{mDMN} \rightarrow \mathrm{TCN}$ influences and stronger $\mathrm{mDMN} \rightarrow \mathrm{TCN}$ influences are associated with less elevated BOLD activity in the TCN areas; and (4) the relationship between TCN $\rightarrow$ mDMN influences and BOLD activity in $\mathrm{mDMN}$ areas is unsystematic.

\section{ROI selection}

As expected, TCN areas of AACC and bilateral AI were activated by the attention task. Past resting-state studies have found that these regions are correlated even when task demand is absent (Menon and Uddin, 2010). Using a novel connectivity measure 
called total interdependence, we further demonstrated that dACC and AI form a distinct functional unit (dACC-AI network) at rest, whose spatial coordinates are highly compatible with the TCN ROIs selected in this study based on task activation (Wen et al., 2012b). For mDMN, we applied group ICA to the resting-state data recorded in the same scanning session, and the ROIs of the mDMN so identified were found to be contained in the task deactivation map (Greicius and Menon, 2004; Buckner et al., 2008; Lin et al., 2011). Time course inspection revealed that attention-elevated BOLD activities in TCN ROIs and attentionsuppressed BOLD activities in $\mathrm{mDMN}$ ROIs were both sustained over the entire trial block (Fig. 1D). These highly replicable blocklevel BOLD responses are attributable to the mixed-blocked and event-related design used in this study (Dosenbach et al., 2006).

\section{$\mathrm{TCN} \rightarrow \mathrm{DMN}$}

TCN is thought to maintain task-level control across multiple trials by issuing signals to regulate other brain areas and configure the moment-to-moment information processing of the brain. In the current formulation of the theory, the areas that are thought to be influenced by these control signals are task-positive areas (Dosenbach et al., 2008; Wang et al., 2010; Zanto et al., 2011). We extend the theory by showing that the domain of influence of TCN also includes task-negative areas, specifically the areas of $\mathrm{mDMN}$, and that the top-down influences of TCN over these areas facilitate goal-oriented behavior (Fig. 3I). Because $\mathrm{mDMN}$ is reliably associated with self-related processes, in tasks requiring externally oriented attention, such as the one used in this study, mDMN activity may be conceived of as a source of internal interference or noise (Buckner et al., 2008; Broyd et al., 2009; Stawarczyk et al., 2011). This notion is supported by studies in which insufficient deactivation of $\mathrm{mDMN}$ is found to be detrimental for behavioral performance in both normal populations and patients with brain disorders (Lustig et al., 2003; Mason et al., 2007; Christoff et al., 2009; Anticevic et al., 2010; Spreng and Schacter, 2012). In this sense, our finding that stronger TCN $\rightarrow$ $\mathrm{mDMN}$ is associated with enhanced behavioral performance suggests that TCN plays a role in the suppression of this internal noise.

\section{$\mathrm{DMN} \rightarrow \mathrm{TCN}$}

Task-triggered interactions in large-scale cortical networks are likely to be bidirectional. No theory has appeared to date to account for how signals arising from mDMN may influence TCN. Our finding that higher mDMN BOLD level is associated with stronger $\mathrm{mDMN} \rightarrow \mathrm{TCN}$ and stronger $\mathrm{mDMN} \rightarrow \mathrm{TCN}$ is associated with less elevated BOLD level in TCN and degraded performance (Figs. 3J, 4D) further supports the notion that $\mathrm{mDMN}$ activity represents a source of internal noise that adversely impacts behavior by sending signals to disrupt task set control functions performed by TCN in demanding tasks. At the individual area level, $\mathrm{mDMN} \rightarrow \mathrm{dACC}$ is strictly behavior degrading, in agreement with the idea that dACC maintains and enforces task rules (Dosenbach et al., 2007; Woodward et al., 2008; Schulz et al., 2011) and as such is more vulnerable to interference from both internal and external sources of noise (Buckner et al., 2008; Corbetta et al., 2008).

\section{Causal interactions and regional BOLD activities}

At the ROI level, significant correlation mainly existed between causal influences and BOLD levels in the target areas. For example, increased dACC $\rightarrow$ PCC is associated with more depressed PCC BOLD level, whereas increased PCC $\rightarrow \mathrm{dACC}$ is associated with less elevated dACC BOLD level. In conjunction with the finding that PCC BOLD level is negatively correlated with both $\mathrm{RT}$ and accuracy, these results may suggest that dACC suppresses internal noise by lowering PCC activity, and at the same time, PCC interferes with task control by lowering dACC activity. At the network level, $\mathrm{mDMN} \rightarrow \mathrm{TCN}$ are related to reduced activity levels in TCN, but in the opposite direction, no consistent patterns are seen (Fig. 4C,D). The fact that less suppressed mDMN BOLD level is associated with stronger mDMN $\rightarrow$ TCN and stronger $\mathrm{mDMN} \rightarrow$ TCN generally predicts less elevated TCN BOLD and worse performance suggests that phenomena typically attributed to $\mathrm{mDMN}$, such as attentional lapses and mind wandering, may be partly achieved through its adverse impact on task control structures. Conversely, the lack of a consistent pattern between TCN $\rightarrow \mathrm{mDMN}$ and $\mathrm{mDMN}$ BOLD level may suggest that control signals from TCN to $\mathrm{mDMN}$ regulate different mDMN nodes using different mechanisms.

\section{Methodology considerations}

Temporal correlation and coherence are symmetric measures and do not yield directional information, but neural interactions are directional. In particular, when signals traveling in opposite directions are hypothesized to have different functional meanings, decomposition of neural interactions into their directional components becomes necessary. Commonly used methods, such as structural equation modeling (McIntosh and Gonzalez-Lima, 1994) and dynamic causal modeling (Friston et al., 2003), depend on a preexisting theoretical framework. Granger causality, in contrast, is based on time series prediction, is more data driven, and has proven to be a powerful tool for analyzing electrophysiological data (Brovelli et al., 2004; Bollimunta et al., 2008, 2011). Although the application of Granger causality to fMRI data is increasing (Rypma et al., 2006; Bressler et al., 2008; Deshpande et al., 2008; Duann et al., 2009; Rypma and Prabhakaran, 2009; Zhou et al., 2009; Biswal et al., 2010; Hwang et al., 2010; Schippers et al., 2010; Jiao et al., 2011; Ge et al., 2012; Stephan and Roebroeck, 2012; Wen et al., 2012a), concerns have been raised over the neural interpretability of the results (David et al., 2008; Smith et al., 2011). The main contention is whether fMRI-level Granger causality can recover neural-level network connectivity (Roebroeck et al., 2005; Deshpande et al., 2010, Schippers et al., 2011). Over timescales resolvable by fMRI, interactions in large-scale cortical networks triggered by cognitive paradigms are likely to be bidirectional, and in cognitive neuroscience, it is often the changes of neuronal activity across experimental conditions that are important for inferring mechanisms. In this context, rather than asking whether there is a causal influence from A to B, a more pertinent question is: are changes in Granger causality at the fMRI level and that at the neuronal level related (Roebroeck et al., 2005; Biswal et al., 2010; Wen et al., 2012a)? Using analytical methods and numerical simulations, we found a monotonic relationship between the magnitude of Granger causality at the fMRI level and that at the neural level (Rangarajan et al., 2011), suggesting that increase or decrease of fMRI-level Granger causality as the experimental parameter is varied and can be interpreted in terms of the corresponding increase or decrease of neuronal-level Granger causality. The simulation, along with the extant neuroscience literature, provides the interpretational basis for this study in which levels of behavioral performance are treated as such an experimental parameter.

Several additional remarks are in order. (1) At the individual subject level, the relationship between brain and behavioral data is very noisy, making it hard to detect reliable correlations. Our 
method of averaging across blocks and subjects can effectively enhance the signal-to-noise ratio. We tested whether data from a few subjects can dominate the results by normalizing each subject's data before averaging and obtained almost identical results, precluding such a possibility. (2) Only pairwise Granger causality is considered in this study. This is reasonable given that our hypotheses did not specify the pathways along which the influences are transmitted. Conditional Granger causality is capable of yielding additional information on the relationship between causal influences and anatomical connections (Chen et al., 2006; Ding et al., 2006). Because voxel-level BOLD signals were used and the number of voxels across the six ROIs is large, a full conditional Granger causality analysis of the present data is not practical. (3) Significance test on individual Granger causality values was not performed. We relied instead on their collective relationship with other variables such as performance to assess their functional meaning. (4) Average BOLD responses in Figure $1 D$ and residual BOLD fluctuations in Figure $2 D$ may reflect different aspects of cognitive processing in much the same way as eventrelated potentials, and ongoing oscillations reflect different aspects of cognitive processing in electrophysiology. In this study, average BOLD responses were subtracted to obtain residual BOLD fluctuations for Granger causality analysis. Past electrophysiology work has shown that trial-to-trial variability of eventrelated responses may adversely influence Granger causality analysis of ongoing activity (Wang et al., 2008). Although to what extent this issue may apply to fMRI data is not clear, the impact is likely to be small, the reason being that the residual BOLD time series are found to be stationary. (5) Slow TRs have always been a source of concern for time-series-based connectivity analysis. However, the advent of faster sampling fMRI techniques (Feinberg et al., 2010) is beginning to alleviate this concern. Faster TRs can help better preserve the relationship between neural-level Granger causality and fMRI-level Granger causality (Seth et al., 2013).

\section{References}

Abler B, Roebroeck A, Goebel R, Höse A, Schönfeldt-Lecuona C, Hole G, Walter H (2006) Investigating directed influences between activated brain areas in a motor-response task using fMRI. Magn Reson Imaging 24:181-185. CrossRef Medline

Aguirre GK, Zarahn E, D’Esposito M (1998) The variability of human, BOLD hemodynamic responses. Neuroimage 8:360-369. CrossRef Medline

Anticevic A, Repovs G, Shulman GL, Barch DM (2010) When less is more: TPJ and default network deactivation during encoding predicts working memory performance. Neuroimage 49:2638-2648. CrossRef Medline

Bennett C, Baird AA, Miller M, Wolford G (2009) Neural correlates of interspecies perspective taking in the post-mortem Atlantic Salmon: an argument for multiple comparisons correction. Neuroimage 47:S125S125.

Birn RM, Diamond JB, Smith MA, Bandettini PA (2006) Separating respiratory-variation-related fluctuations from neuronal-activity-related fluctuations in fMRI. Neuroimage 31:1536-1548. CrossRef Medline

Biswal BB, Eldreth DA, Motes MA, Rypma B (2010) Task-dependent individual differences in prefrontal connectivity. Cereb Cortex 20:21882197. CrossRef Medline

Bollimunta A, Chen Y, Schroeder CE, Ding M (2008) Neuronal mechanisms of cortical alpha oscillations in awake-behaving macaques. J Neurosci 28:9976-9988. CrossRef Medline

Bollimunta A, Mo J, Schroeder CE, Ding M (2011) Neuronal mechanisms and attentional modulation of corticothalamic alpha oscillations. J Neurosci 31:4935-4943. CrossRef Medline

Bonnelle V, Ham TE, Leech R, Kinnunen KM, Mehta MA, Greenwood RJ, Sharp DJ (2012) Salience network integrity predicts default mode network function after traumatic brain injury. Proc Natl Acad Sci U S A 109:4690-4695. CrossRef Medline
Botvinick MM, Cohen JD, Carter CS (2004) Conflict monitoring and anterior cingulate cortex: an update. Trends Cogn Sci 8:539-546. CrossRef Medline

Bressler SL, Tang W, Sylvester CM, Shulman GL, Corbetta M (2008) Topdown control of human visual cortex by frontal and parietal cortex in anticipatory visual spatial attention. J Neurosci 28:10056-10061. CrossRef Medline

Brovelli A, Ding M, Ledberg A, Chen Y, Nakamura R, Bressler SL (2004) Beta oscillations in a large-scale sensorimotor cortical network: directional influences revealed by Granger causality. Proc Natl Acad Sci U S A 101:9849-9854. CrossRef Medline

Broyd SJ, Demanuele C, Debener S, Helps SK, James CJ, Sonuga-Barke EJ (2009) Default-mode brain dysfunction in mental disorders: a systematic review. Neurosci Biobehav Rev 33:279-296. CrossRef Medline

Buckner RL, Andrews-Hanna JR, Schacter DL (2008) The brain's default network: anatomy, function, and relevance to disease. Ann N Y Acad Sci 1124:1-38. CrossRef Medline

Chen Y, Bressler SL, Ding M (2006) Frequency decomposition of conditional Granger causality and application to multivariate neural field potential data. J Neurosci Methods 150:228-237. CrossRef Medline

Christoff K, Gordon AM, Smallwood J, Smith R, Schooler JW (2009) Experience sampling during fMRI reveals default network and executive system contributions to mind wandering. Proc Natl Acad Sci U S A 106:8719-8724. CrossRef Medline

Church JA, Fair DA, Dosenbach NU, Cohen AL, Miezin FM, Petersen SE, Schlaggar BL (2009) Control networks in paediatric Tourette syndrome show immature and anomalous patterns of functional connectivity. Brain 132:225-238. CrossRef Medline

Collins DL, Neelin P, Peters TM, Evans AC (1994) Automatic 3D intersubject registration of MR volumetric data in standardized Talairach space. J Comput Assist Tomogr 18:192-205. CrossRef Medline

Corbetta M, Patel G, Shulman GL (2008) The reorienting system of the human brain: from environment to theory of mind. Neuron 58:306-324. CrossRef Medline

David O, Guillemain I, Saillet S, Reyt S, Deransart C, Segebarth C, Depaulis A (2008) Identifying neural drivers with functional MRI: an electrophysiological validation. PLoS Biol 6:2683-2697. CrossRef Medline

Deshpande G, Hu X, Stilla R, Sathian K (2008) Effective connectivity during haptic perception: a study using Granger causality analysis of functional magnetic resonance imaging data. Neuroimage 40:1807-1814. CrossRef Medline

Deshpande G, Sathian K, Hu X (2010) Effect of hemodynamic variability on Granger causality analysis of fMRI. Neuroimage 52:884-896. CrossRef Medline

Ding J, Powell D, Jiang Y (2009) Dissociable frontal controls during visible and memory-guided eye-tracking of moving targets. Hum Brain Mapp 30:3541-3552. CrossRef Medline

Ding M, Bressler SL, Yang W, Liang H (2000) Short-window spectral analysis of cortical event-related potentials by adaptive multivariate autoregressive modeling: data preprocessing, model validation, and variability assessment. Biol Cybern 83:35-45. CrossRef Medline

Ding M, Chen Y, Bressler SL (2006) Granger causality: basic theory and application to neuroscience. In: Handbook of time series analysis (Schelter B, Winderhalder M, Timmer J, ed), pp 437-460. Berlin: Wiley-VCH.

Dosenbach NU, Visscher KM, Palmer ED, Miezin FM, Wenger KK, Kang HC, Burgund ED, Grimes AL, Schlaggar BL, Petersen SE (2006) A core system for the implementation of task sets. Neuron 50:799-812. CrossRef Medline

Dosenbach NU, Fair DA, Miezin FM, Cohen AL, Wenger KK, Dosenbach RA, Fox MD, Snyder AZ, Vincent JL, Raichle ME, Schlaggar BL, Petersen SE (2007) Distinct brain networks for adaptive and stable task control in humans. Proc Natl Acad Sci 104:11073-11078. CrossRef Medline

Dosenbach NU, Fair DA, Cohen AL, Schlaggar BL, Petersen SE (2008) A dual-networks architecture of top-down control. Trends Cogn Sci 12:99105. CrossRef Medline

Duann JR, Ide JS, Luo X, Li CR (2009) Functional connectivity delineates distinct roles of the inferior frontal cortex and presupplementary motor area in stop signal inhibition. J Neurosci 29:10171-10179. CrossRef Medline

Durbin J, Watson GS (1950) Testing for serial correlation in least squares regression I. Biometrika 37:409-428. Medline

Fan J, Gu X, Liu X, Guise KG, Park Y, Martin L, de Marchena A, Tang CY, 
Minzenberg MJ, Hof PR (2011) Involvement of the anterior cingulate and frontoinsular cortices in rapid processing of salient facial emotional information. Neuroimage 54:2539-2546. CrossRef Medline

Feinberg DA, Moeller S, Smith SM, Auerbach E, Ramanna S, Gunther M, Glasser MF, Miller KL, Ugurbil K, Yacoub E (2010) Multiplexed echo planar imaging for sub-second whole brain FMRI and fast diffusion imaging. PLoS One 5:e15710. CrossRef Medline

Fitzgerald KD, Stern ER, Angstadt M, Nicholson-Muth KC, Maynor MR, Welsh RC, Hanna GL, Taylor SF (2010) Altered function and connectivity of the medial frontal cortex in pediatric obsessive-compulsive disorder. Biol Psychiatry 68:1039-1047. CrossRef Medline

Fox MD, Snyder AZ, Vincent JL, Corbetta M, Van Essen DC, Raichle ME (2005) The human brain is intrinsically organized into dynamic, anticorrelated functional networks. Proc Natl Acad Sci U S A 102:9673-9678. CrossRef Medline

Fox MD, Zhang D, Snyder AZ, Raichle ME (2009) The global signal and observed anticorrelated resting state brain networks. J Neurophysiol 101: 3270-3283. CrossRef Medline

Friston KJ, Ashburner J, Frith CD, Poline JB, Heather JD, Frackowiak R (1995) Spatial registration and normalization of images. Hum Brain Mapp 3:165-189. CrossRef

Friston KJ, Harrison L, Penny W (2003) Dynamic causal modelling. Neuroimage 19:1273-1302. CrossRef Medline

Gao W, Lin W (2012) Frontal parietal control network regulates the anticorrelated default and dorsal attention networks. Hum Brain Mapp 33: 192-202. CrossRef Medline

Garrett DD, Kovacevic N, McIntosh AR, Grady CL (2011) The importance of being variable. J Neurosci 31:4496-4503. CrossRef Medline

Gavrilescu M, Shaw ME, Stuart GW, Eckersley P, Svalbe ID, Egan GF (2002) Simulation of the effects of global normalization procedures in functional MRI. Neuroimage 17:532-542. CrossRef Medline

Ge T, Feng J, Grabenhorst F, Rolls ET (2012) Componential Granger causality, and its application to identifying the source and mechanisms of the top-down biased activation that controls attention to affective vs sensory processing. Neuroimage 59:1846-1858. CrossRef Medline

Geweke J (1982) Measurement of linear-dependence and feedback between multiple time-series. J Am Stat Assoc 77:304-313. CrossRef

Granger CW (1967) Investigating causal relations by econometric models and cross-spectral methods. Econometrica 37:424-443.

Greicius MD, Menon V (2004) Default-mode activity during a passive sensory task: uncoupled from deactivation but impacting activation. J Cogn Neurosci 16:1484-1492. CrossRef Medline

Hamilton JP, Chen G, Thomason ME, Schwartz ME, Gotlib IH (2011) Investigating neural primacy in Major Depressive Disorder: multivariate Granger causality analysis of resting-state fMRI time-series data. Mol Psychiatry 16:763-772. CrossRef Medline

Hwang K, Velanova K, Luna B (2010) Strengthening of top-down frontal cognitive control networks underlying the development of inhibitory control: a functional magnetic resonance imaging effective connectivity study. J Neurosci 30:15535-15545. CrossRef Medline

Jiao Q, Lu G, Zhang Z, Zhong Y, Wang Z, Guo Y, Li K, Ding M, Liu Y (2011) Granger causal influence predicts BOLD activity levels in the default mode network. Hum Brain Mapp 32:154-161. CrossRef Medline

Junghöfer M, Schupp HT, Stark R, Vaitl D (2005) Neuroimaging of emotion: empirical effects of proportional global signal scaling in fMRI data analysis. Neuroimage 25:520-526. CrossRef Medline

Kerns JG, Cohen JD, MacDonald AW 3rd, Cho RY, Stenger VA, Carter CS (2004) Anterior cingulate conflict monitoring and adjustments in control. Science 303:1023-1026. CrossRef Medline

Kwiatkowski D, Phillips PC, Schmidt P, Shin Y (1992) Testing the null hypothesis of stationarity against the alternative of a unit root. J Econ 54: 159-178. CrossRef

Liao W, Qiu C, Gentili C, Walter M, Pan Z, Ding J, Zhang W, Gong Q, Chen H (2010) Altered effective connectivity network of the amygdala in social anxiety disorder: a resting-state fMRI study. PLoS One 5:e15238. CrossRef Medline

Lin P, Hasson U, Jovicich J, Robinson S (2011) A neuronal basis for tasknegative responses in the human brain. Cereb Cortex 21:821-830. CrossRef Medline

Logan GD, Gordon RD (2001) Executive control of visual attention in dualtask situations. Psychol Rev 108:393-434. CrossRef Medline

Lund TE, Madsen KH, Sidaros K, Luo WL, Nichols TE (2006) Non-white noise in fMRI: does modelling have an impact? Neuroimage 29:54-66. CrossRef Medline

Lustig C, Snyder AZ, Bhakta M, O'Brien KC, McAvoy M, Raichle ME, Morris JC, Buckner RL (2003) Functional deactivations: change with age and dementia of the Alzheimer type. Proc Natl Acad Sci U S A 100:1450414509. CrossRef Medline

Macey PM, Macey KE, Kumar R, Harper RM (2004) A method for the removal of global effects from fMRI time series. Neuroimage 22:360-366. CrossRef Medline

Maddock RJ (1999) The retrosplenial cortex and emotion: new insights from functional neuroimaging of the human brain. Trends Neurosci 22: 310-316. Medline

Mason MF, Norton MI, Van Horn JD, Wegner DM, Grafton ST, Macrae CN (2007) Wandering minds: the default network and stimulusindependent thought. Science 315:393-395. CrossRef Medline

McIntosh AR, Gonzalez-Lima F (1994) Structural equation modeling and its application to network analysis in functional brain imaging. Hum Brain Mapp 2:2-22. CrossRef

Menon V (2011) Large-scale brain networks and psychopathology: a unifying triple network model. Trends Cogn Sci 15:483-506. CrossRef Medline

Menon V, Uddin LQ (2010) Saliency, switching, attention and control: a network model of insula function. Brain Struct Funct 214:655-667. CrossRef Medline

Miao X, Wu X, Li R, Chen K, Yao L (2011) Altered connectivity pattern of hubs in default-mode network with Alzheimer's disease: an Granger causality modeling approach. PLoS One 6:e25546. CrossRef Medline

Nelson SM, Dosenbach NU, Cohen AL, Wheeler ME, Schlaggar BL, Petersen SE (2010) Role of the anterior insula in task-level control and focal attention. Brain Struct Funct 214:669-680. Medline

Ossandón T, Jerbi K, Vidal JR, Bayle DJ, Henaff MA, Jung J, Minotti L, Bertrand O, Kahane P, Lachaux JP (2011) Transient suppression of broadband gamma power in the default-mode network is correlated with task complexity and subject performance. J Neurosci 31:14521-14530. CrossRef Medline

Poldrack RA, Mumford JA (2009) Independence in ROI analysis: where is the voodoo? Soc Cogn Affect Neurosci 4:208-213. CrossRef Medline

Rangarajan G, Wen X, Ding M (2011) Linking BOLD-level Granger causality with neural-level Granger causality. Soc Neurosci Abstr 37:621.03.

Roebroeck A, Formisano E, Goebel R (2005) Mapping directed influence over the brain using Granger causality and fMRI. Neuroimage 25:230242. CrossRef Medline

Rogers BP, Morgan VL, Newton AT, Gore JC (2007) Assessing functional connectivity in the human brain by fMRI. Magn Reson Imaging 25:13471357. CrossRef Medline

Rypma B, Prabhakaran V (2009) When less is more and when more is more: the mediating roles of capacity and speed in brain-behavior efficiency. Intelligence 37:207-222. CrossRef Medline

Rypma B, Berger JS, Prabhakaran V, Bly BM, Kimberg DY, Biswal BB, D’Esposito M (2006) Neural correlates of cognitive efficiency. Neuroimage 33:969-979. CrossRef Medline

Sambataro F, Murty VP, Callicott JH, Tan HY, Das S, Weinberger DR, Mattay VS (2010) Age-related alterations in default mode network: impact on working memory performance. Neurobiol Aging 31:839-852. CrossRef Medline

Santhanam P, Coles CD, Li Z, Li L, Lynch ME, Hu X (2011) Default mode network dysfunction in adults with prenatal alcohol exposure. Psychiatry Res 194:354-362. Medline

Sato JR, Hoexter MQ, Castellanos XF, Rohde LA (2012) Abnormal brain connectivity patterns in adults with ADHD: a coherence study. PLoS One 7:e45671. CrossRef Medline

Schippers MB, Roebroeck A, Renken R, Nanetti L, Keysers C (2010) Mapping the information flow from one brain to another during gestural communication. Proc Natl Acad Sci U S A 107:9388-9393. CrossRef Medline

Schippers MB, Renken R, Keysers C (2011) The effect of intra- and intersubject variability of hemodynamic responses on group level Granger causality analysis. Neuroimage 57:22-36. CrossRef Medline

Schulz KP, Bédard AC, Czarnecki R, Fan J (2011) Preparatory activity and connectivity in dorsal anterior cingulate cortex for cognitive control. Neuroimage 57:242-250. CrossRef Medline

Seth AK (2005) Causal connectivity analysis of evolved neural networks during behavior. Network 16:35-54. CrossRef Medline 
Seth AK, Chorley P, Barnett LC (2013) Granger causality analysis of fMRI BOLD signals is invariant to hemodynamic convolution but not downsampling. Neuroimage 65:540-555. CrossRef Medline

Sharp DJ, Beckmann CF, Greenwood R, Kinnunen KM, Bonnelle V, De Boissezon X, Powell JH, Counsell SJ, Patel MC, Leech R (2011) Default mode network functional and structural connectivity after traumatic brain injury. Brain 134:2233-2247. CrossRef Medline

Simpson JR Jr, Snyder AZ, Gusnard DA, Raichle ME (2001) Emotioninduced changes in human medial prefrontal cortex: I. During cognitive task performance. Proc Natl Acad Sci U S A 98:683-687. CrossRef Medline

Smallwood J, Brown K, Baird B, Schooler JW (2012) Cooperation between the default mode network and the frontal-parietal network in the production of an internal train of thought. Brain Res 1428:60-70. CrossRef Medline

Smith AM, Lewis BK, Ruttimann UE, Ye FQ, Sinnwell TM, Yang Y, Duyn JH, Frank JA (1999) Investigation of low frequency drift in fMRI signal. Neuroimage 9:526-533. CrossRef Medline

Smith SM, Miller KL, Salimi-Khorshidi G, Webster M, Beckmann CF, Nichols TE, Ramsey JD, Woolrich MW (2011) Network modelling methods for FMRI. Neuroimage 54:875-891. CrossRef Medline

Spreng RN, Schacter DL (2012) Default network modulation and largescale network interactivity in healthy young and old adults. Cereb Cortex 22:2610-2621. CrossRef Medline

Sridharan D, Levitin DJ, Chafe CH, Berger J, Menon V (2007) Neural dynamics of event segmentation in music: converging evidence for dissociable ventral and dorsal networks. Neuron 55:521-532. CrossRef Medline

Sridharan D, Levitin DJ, Menon V (2008) A critical role for the right frontoinsular cortex in switching between central-executive and default-mode networks. Proc Natl Acad Sci U S A 105:12569-12574. CrossRef Medline

Stawarczyk D, Majerus S, Maquet P, D’Argembeau A (2011) Neural corre- lates of ongoing conscious experience: both task-unrelatedness and stimulus-independence are related to default network activity. PLoS One 6:e16997. CrossRef Medline

Stephan KE, Roebroeck A (2012) A short history of causal modeling of fMRI data. Neuroimage 62:856-863. CrossRef Medline

van Eimeren T, Monchi O, Ballanger B, Strafella AP (2009) Dysfunction of the default mode network in Parkinson disease: a functional magnetic resonance imaging study. Arch Neurol 66:877-883. CrossRef Medline

Wang L, Liu X, Guise KG, Knight RT, Ghajar J, Fan J (2010) Effective connectivity of the fronto-parietal network during attentional control. J Cogn Neurosci 22:543-553. CrossRef Medline

Wang X, Chen Y, Ding M (2008) Estimating Granger causality after stimulus onset: a cautionary note. Neuroimage 41:767-776. CrossRef Medline

Wen X, Yao L, Liu Y, Ding M (2012a) Causal interactions in attention networks predict behavioral performance. J Neurosci 32:1284-1292. CrossRef Medline

Wen X, Mo J, Ding M (2012b) Exploring resting-state functional connectivity with total interdependence. Neuroimage 60:1587-1595. CrossRef Medline

Woodward TS, Metzak PD, Meier B, Holroyd CB (2008) Anterior cingulate cortex signals the requirement to break inertia when switching tasks: a study of the bivalency effect. Neuroimage 40:1311-1318. CrossRef Medline

Zanto TP, Rubens MT, Thangavel A, Gazzaley A (2011) Causal role of the prefrontal cortex in top-down modulation of visual processing and working memory. Nat Neurosci 14:656-661. CrossRef Medline

Zarahn E, Aguirre GK, D’Esposito M (1997) Empirical analyses of BOLD fMRI statistics. I. Spatially unsmoothed data collected under nullhypothesis conditions. Neuroimage 5:179-197. CrossRef Medline

Zhou Z, Ding M, Chen Y, Wright P, Lu Z, Liu Y (2009) Detecting directional influence in fMRI connectivity analysis using PCA based Granger causality. Brain Research 1289:22-29. CrossRef Medline 